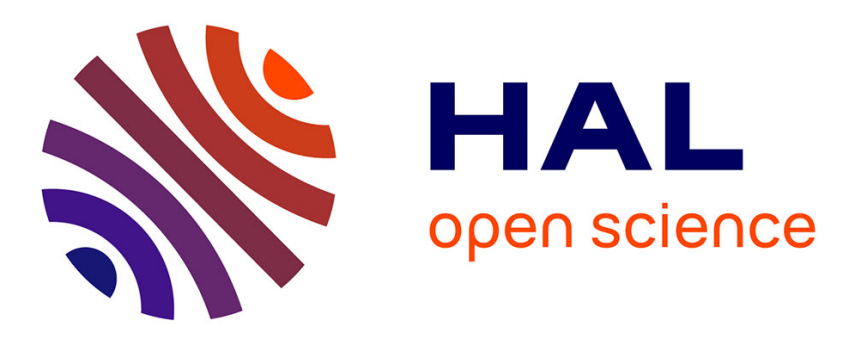

\title{
Abnormal cortical brain integration of somatosensory afferents in ALS
}

Sina Sangari, Alain Giron, Guillaume Marrelec, Pierre-François Pradat, Véronique Marchand-Pauvert

\section{- To cite this version:}

Sina Sangari, Alain Giron, Guillaume Marrelec, Pierre-François Pradat, Véronique Marchand-Pauvert. Abnormal cortical brain integration of somatosensory afferents in ALS. Clinical Neurophysiology, In press, 129 (4), pp.874-884. 10.1016/j.clinph.2017.12.008 . hal-01688635

\section{HAL Id: hal-01688635 \\ https://hal.sorbonne-universite.fr/hal-01688635}

Submitted on 19 Jan 2018

HAL is a multi-disciplinary open access archive for the deposit and dissemination of scientific research documents, whether they are published or not. The documents may come from teaching and research institutions in France or abroad, or from public or private research centers.
L'archive ouverte pluridisciplinaire HAL, est destinée au dépôt et à la diffusion de documents scientifiques de niveau recherche, publiés ou non, émanant des établissements d'enseignement et de recherche français ou étrangers, des laboratoires publics ou privés. 


\section{Title}

\section{Abnormal cortical brain integration of somatosensory afferents in ALS}

\section{Author names and affiliations}

Sina SANGARI ${ }^{1}$, Alain GIRON ${ }^{1}$, Guillaume MARRELEC ${ }^{1}$, Pierre-François PRADAT $^{1,2}$ \& Véronique MARCHAND-PAUVERT ${ }^{1}$.

${ }^{1}$ Sorbonne Universités, UPMC Univ Paris 06, CNRS, Inserm, Laboratoire d'Imagerie Biomédicale, F-75013 Paris, France

${ }^{2}$ Département de Neurologie, AP-HP, Hôpital Pitié-Salpêtrière, F-75013 Paris, France

\section{Corresponding author}

Pr. Veronique Marchand-Pauvert (PhD)

Laboratoire d'Imagerie Biomédicale

Centre de Recherche Biomédicale des Cordeliers, Escalier A, 3e étage

15 rue de l'Ecole de Médecine

75006 Paris, France

veronique.marchand-pauvert@inserm.fr

\section{Acknowledgments}

The authors gratefully acknowledge Dr N. Leforestier, Dr T. Lenglet, Dr F. Salachas, Dr G. Bruneteau and Dr V. Meininger for their help in patient recruitment, and Dr R. MorizotKoutlidis for her contribution for the experimental design of SEP recordings. Our gratitude is also extended to S. Blancho for her assistance in obtaining the approval of the local ethics committee and for monitoring the project. We also thank Caroline Iglesias for her invaluable help in data acquisition. Finally, we thank Dr Peter Bede for his valuable comments.

We have no conflicts of interest to report.

This work was supported by IRME (ID RCB 2012-A00016-37) and ANR (ANR-12-JSV40007- 01). S. Sangari was supported by grants from UPMC and AFM-Téléthon. 


\section{$\underline{\text { Abstract }}$}

Objectives. Infraclinical sensory alterations have been reported at early stages of amyotrophic lateral sclerosis (ALS). While previous studies mainly focused on early somatosensory evoked potentials (SEPs), late SEPs, which reflect on cortical pathways involved in cognitivemotor functions, are relatively underinvestigated. Early and late SEPs were compared to assess their alterations in ALS.

Methods. Median and ulnar nerves were electrically stimulated at the wrist, at 9 times the perceptual threshold, in 21 ALS patients without clinical evidence of sensory deficits, and 21 age- and gender-matched controls. SEPs were recorded at the Erb point using surface electrodes and using a needle inserted in the scalp, in front of the primary somatosensory area (with reference electrode on the ear lobe).

Results. Compared to controls, ALS patients showed comparable peripheral (N9) and early cortical component (N20, P25, N30) reductions, while the late cortical components (N60, P100) were more depressed than the early ones.

Conclusions. The peripheral sensory alteration likely contributed to late SEP depression to a lesser extent than that of early SEPs.

Significance. Late SEPs may provide new insights on abnormal cortical excitability affecting brain areas involved in cognitive-motor functions.

\section{Highlights}

- Subclinical peripheral sensory deficits may influence cortical excitability in ALS

- Sensory dysfunction may contribute to cortical excitability changes of motor and premotor areas

- Neural processing for cognitive-motor control may be intrinsically altered in ALS 


\section{$\underline{\text { Keywords }}$}

Somatosensory Evoked Potentials

Amyotrophic Lateral Sclerosis

Sensory impairment

Cortical excitability

Human

\section{Abbreviations}

ALS: amyotrophic lateral sclerosis

MT: motor threshold

MRI: magnetic resonance imaging

PT: perceptual threshold

S1: primary somatosensory area

S2: secondary somatosensory area

SD: standard deviation

SEP: somatosensory evoked potential 


\section{Introduction}

Amyotrophic Lateral Sclerosis (ALS) is an adult-onset neurodegenerative condition characterized by the loss of motor neurons at cortical, brainstem and spinal levels (Kiernan et al., 2011). ALS is widely considered as a pure motor degeneration; sensory impairment is not a recognised feature of ALS or regarded as secondary to motor impairment (Fincham and Van Allen, 1964; Feller et al., 1966; Schulte-Mattler et al., 1999). However, in addition to the 10 $\%$ patients describing frank paraesthesia and neuropathic pain, sensory impairments have been reported in up to $60 \%$ patients, including abnormal vibration, cutaneous and heat thresholds. (Feller et al., 1966; Dyck et al., 1975; Kawamura et al., 1981; Mulder et al., 1983; Bosch et al., 1985; Gregory et al., 1993; Theys et al., 1999; Hammad et al., 2007; Isak et al., 2016). Furthermore, several studies demonstrated a loss of large-caliber cutaneous afferents and dorsal column demyelination at lumbar level (Feller et al., 1966; Dyck et al., 1975; Tohgi et al., 1977; Kawamura et al., 1981; Bradley et al., 1983; di Trapani et al., 1986; Heads et al., 1991; Shefner et al., 1991; Hammad et al., 2007; Vaughan et al., 2015). Furthermore, postmortem studies have also confirmed the degeneration of spinal ascending tracts (Swash et al., 1988; Williams et al., 1990; Takahashi et al., 1992). In line with these data, multi-parametric spinal cord magnetic resonance imaging (MRI) has shown dorsal column alterations at the cervical level in ALS patients with limited motor deficits and no clinical signs of sensory impairment (Cohen-Adad et al., 2013; Iglesias et al., 2015), confirming that sensory alterations can manifest in parallel to motor impairment but to a lesser degree and with slower progression (Kawamura et al., 1981; Mulder et al., 1983; Cosi et al., 1984; Zanette et al., 1990; Heads et al., 1991; Shefner et al., 1991; Gregory et al., 1993; Mondelli et al., 1993; Theys et al., 1999; Hammad et al., 2007). Finally, recent studies using the superoxide dismutase 1 (SOD1) mouse model have reported disorganization of muscle spindles, primary and secondary sensory endings (group Ia and group II afferents) at early presymptomatic stages, and $50 \%$ axonal loss in the dorsal roots at the late presymptomatic stage (Fischer et al., 2005; Sábado et al., 2014). These results further suggest that sensory impairment in ALS is unlikely to be merely a consequence of motor impairment.

Somatosensory evoked potentials (SEPs) by peripheral nerve stimulation are captured in electroencephalogram (EEG) and allow the quantitative assessment of the integrity of the somatosensory pathway. They are divided into three components, including i) the peripheral potential (N9) reflecting the afferent volley at the level of the plexus brachialis, ii) the early cortical SEPs (N20, P25, N30 and P35) whose activity sources are located in the primary somatosensory area (S1) and the motor cortex, and iii) the late cortical SEPs (P45, N60, P100 
and N120) involving the secondary somatosensory area (S2) and associative areas (Giblin, 1964; Woolsey et al., 1979; Drechsler, 1980; Shahani et al., 1980, Small, 1980; Anziska and Cracco, 1983; Allison et al., 1992; Mauguiere et al., 1997, 1999; Urbano et al., 1997; Torquati et al., 2002; Mauguiere, 2005; Papadelis et al., 2011; Aspell et al., 2012; Saradjian et al., 2013). Early SEPs mainly depend on peripheral inputs and are primarily involved in stimulus perception (intensity, location) (Halgren et al., 1998; Torquati et al., 2002; Lim et al., 2012). Late SEPs have been less studied than early SEPs and consequently, much less characterized. However, it has been shown that late SEPs depend on the excitability of more complex cortico-subcortical networks, involved in higher-order functions (texture, shape recognition) and in cognitive and limbic projections through the insula, amygdala and hippocampus (Mauguiere et al., 1997; Halgren et al., 1998; Hari and Forss, 1999; Torquati et al., 2002; Eickhoff et al., 2006a, b; Papadelis et al., 2011; Lim et al., 2012). The evaluation of SEP in ALS gave rise to strikingly inconsistent results, due to differences in sample sizes, disease stages, the presence or absence of sensory impairment, and reference electrode placement (cephalic vs. extra-cephalic) (Bosch et al., 1985; Facco et al., 1989; Gregory et al., 1993; Mondelli et al., 1993; Theys et al., 1999; de Carvalho and Swash, 2000). Abnormal early SEPs produced by upper limb nerve stimulation have been reported in $35 \%$ patients (Matheson et al., 1986; Radtke et al., 1986; Constantinovici, 1993), and have been found delayed and/or reduced in amplitude (Pugdahl et al., 2006; Hammad et al., 2007). Moreover, altered amplitude has been reported at the latency of N60 without any associated modification of N9 or early cortical SEPs (Cosi et al., 1984; Bosch et al., 1985; Dasheiff et al., 1985). This suggests that altered SEPs in ALS may result from sensory impairment and/or altered corticosubcortical excitability, probably mediated by thalamus pathology, S1 or S2 atrophy at later stages of the disease (Smith, 1960; Kew et al., 1994; Zanette et al., 1996; Filippini et al., 2010; Canu et al., 2011; Li et al., 2012; Bede et al., 2013; Chapman et al., 2014; Verstraete et al., 2014; Devine et al., 2015). Lastly, it is conceivable that the integrative properties of cortico-subcortical networks are altered in ALS, which leads to cortical excitability alterations, as reported during disease progression with incremental pyramidal cells and inhibitory interneurons pathology (Mills and Nithi, 1997; Eisen and Swash, 2001; Zanette et al., 2002a, b; de Carvalho et al., 2003; Mills, 2003; Vucic et al., 2008; Floyd et al., 2009; Menon et al., 2015a,b).

The possible involvement of somatosensory alterations (deafferentation and altered integrative neural properties) is not commonly considered in the pathogenesis of ALS. We have recently reported a correlation between structural changes in ascending sensory 
pathways at cervical level (using diffusion spinal imaging) and altered transmission of peripheral afferent inputs (depression of N9 and N20) in patients exhibiting weak distal motor dysfunctions without overt clinical signs of sensory impairment (Iglesias et al., 2015). Furthermore, we identified altered transmission of muscle spindle sensory inputs to spinal motoneurons supplying clinically unaffected muscles, and we proposed that this could contribute to motoneuron hyperexcitability (Sangari et al., 2016). In this present study, we have compared early and late SEPs induced by median and ulnar nerve stimulations in the same group of ALS patients in order to determine whether the changes observed at the cortical level are directly linked to the peripheral subclinical sensory defect and/or associated with perturbed cortico-subcortical integrative functions. Furthermore, given that early and late SEPs likely involve motor and non-motor areas, we wondered whether signals generated at these levels were altered to the same extent by comparing early and late SEPs. Late SEPs are considerably less investigated in ALS than early SEPs.

\section{$\underline{\text { 2. Materials \& Methods }}$}

\subsection{Ethics and participants}

The study was performed in accordance with the Declaration of Helsinki, and has been approved by the ethics committee: Ile-de-France VI (Pitié-salpêtrière). All participants gave written consent. The data were collected from the same groups of subjects as described by Iglesias et al., 2015 and Sangari et al., 2016: 21 patients (1 familial case; 16 males; age $56.3 \pm$ 2.1, 37-76 y.o.; see Table 1) and 21 controls (16 males; age 56.6 $\pm 2.1,33-73$ y.o.). The mean duration of clinical motor signs was $26.6 \pm 3.6$ months and 20/21 patients took riluzole (100 $\mathrm{mg} /$ day) and $\alpha$-tocopherol (1000 mg/ day). The inclusion criteria were: 1) 'probable' or 'definite' ALS according to the El Escorial criteria, 2) weakness in hand muscles at least on one side, 3) absence of peripheral neuropathy and 4) no clinical signs of sensory deficits. Patients were investigated on the more affected side or on the dominant side when both sides were equally affected. Controls were stimulated on their dominant side (Oldfield, 1971). Table 1 shows ALSFRS-r scores reflecting the global functional disability, the ALSFRS-r sub-scores for hand functions (writing and feeding), and force measured using the manual muscle testing (MMT) for thumb abduction and distal phalanx flexion of finger III).

\section{Insert Table 1}




\subsection{SEPs recordings}

Percutaneous electrical stimulations were applied to median and ulnar nerves at the wrist level (bipolar electrodes, $0.5 \mathrm{~cm}^{2}, 1-\mathrm{cm}$ apart; 1-ms rectangular electrical stimulation; DS7A, Digitimer Ltd, Hertfordshire, UK). The resulting afferent volley was recorded using surface electrodes placed in the supraclavicular fosses (Erb point): one ipsilateral to the stimulations and the other one, on the other side (reference). The brain signal was recorded using a needle electrode implanted in the skin, face to $\mathrm{S} 1$ area contralateral to peripheral nerve stimulations (4-cm lateral and 2-cm posterior to vertex point), and two reference electrodes were placed on each ear lobe. Signal capture was limited to 30-3000 Hz-bandwidths, and amplification was 10000 (D360 8-Channel Patient Amplifier, Digitimer Ltd, Hertfordshire, UK). Peripheral and brain signals were digitalized (2-kHz sampling rate) for subsequent analysis (Power 1401 and Signal Software, CED, Cambridge, UK). The experiment started by evaluating the perceptual thresholds (PT) for both peripheral nerve stimulations, and conditioning stimulus intensity was fixed at 9 x PT for recordings. A total number of 600 stimuli were delivered to both nerves, distributed over 3 recording sequences; one recording sequence included 200 stimuli applied to median nerve and 200 to ulnar nerve, delivered randomly at $2 \mathrm{~Hz}$.

\subsection{Data analysis}

Mean EEG signal from each participant was normalized to twice the standard deviation $(2 \times \mathrm{SD})$ calculated over a 100 -ms period of the prestimulus activity, excluding stimulus artifacts (see Iglesias et al., 2015). Peaks and onsets latencies of each potential were evaluated for each subject. Then, EEG signal was rectified and SEP area was measured to better appreciate their modulation. Area of each potential was estimated using a fixed analysis window determined according to the mean potential latency and duration estimated in each subject; the analysis window was similar for ALS and controls (see results). In order to further compare the changes in SEP area in ALS, for the different component (ALS patient area reduction), we calculated the mean area of each SEP component (N9, N20, P25, N30,

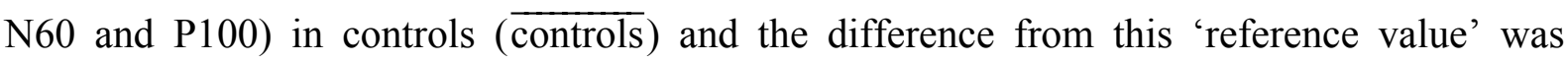
calculated in each patient, and for each component. Then, the difference was expressed as a percentage of mean N9 $(\overline{\mathrm{N} 9})$ and of mean $\mathrm{N} 20(\overline{\mathrm{N} 20})$ area calculated in controls, for peripheral (N9) and cortical SEPs, respectively. The level of SEP depression in ALS was thus calculated according to this equation: 


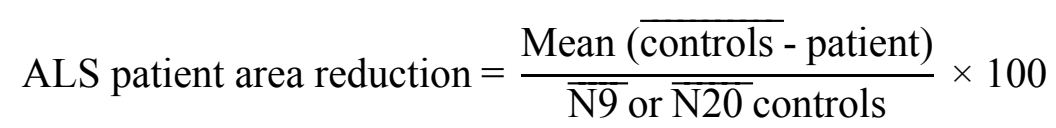

Analysis focused on N9, N20, P25, N30, N60 and P100 components, excluding P35 and N120 because their origin has not been characterized (Small, 1980; Anziska and Cracco, 1983; Bosch et al., 1985; Urbano et al., 1997; Hari and Forss, 1999; Mauguiere et al., 1999; Hoshiyama and Kakigi, 2001; Mauguiere, 2005; Papadelis et al., 2011).

\subsection{Statistical analysis}

Data distribution and variances were checked for parametric testing; alternatively, non-parametric tests were used. First, the level of EEG pre-stimulus activity was compared between controls and ALS patients with unpaired $t$ test. Then, two-way ANOVA was performed to compare the onset and peak latencies of early and late SEPs between patients and controls (SEPs x groups). Subsequently, the SEP size between groups (controls vs. ALS) and the level of SEP depression in patients were compared using Kruskall-Wallis $H$ test, and post-hoc Tukey test was used for pairwise comparisons. Pearson product moment correlation was performed to determine whether changes in SEP size were correlated. Finally, multivariate analyses were performed to investigate the change in SEPs according to motor dysfunctions. A probability $(P)$ value of $<0.05$ was considered statistically significant. Results were expressed as mean \pm standard error of the mean (SEM).

\section{Results}

Figure 1 illustrates the averaged waveform recorded at the Erb point and over S1 area (normalized to $2 \mathrm{x}$ SD prestimulus activity) in 2 individuals. The mean waveforms $(\mathrm{N}=600$ stimuli), conditioned by median nerve stimulation, in one control (dark line) and in one ALS patient (grey line; Fig. 1A) show that the size of N9 and of cortical SEPs were reduced in the patient, compared to the control. The grand average pictured in Figure 1B shows similar results in the group of ALS patients, compared to the group of controls. All potentials were reduced in the patient group compared to the control group, regardless of the conditioning stimuli (median or ulnar nerve stimulation).

\section{Insert Figure 1}

Table 2 shows the level of prestimulus activity and the latency of each potential observed in controls (dark) and in ALS patients (grey) for the median and ulnar nerves. No difference in the level of prestimulus activity (in $\mu \mathrm{V} \pm \mathrm{SEM}$ ) was observed between groups, 
in either nerve (Table 2; unpaired $t$ test, Erb point: $0.07<P<0.08$; S1 area: $0.09<P<0.12$ ). The onset and peak latencies (in $\mathrm{ms} \pm \mathrm{SEM}$ ) for each component were not significantly different between groups, in either nerve (Table 2; two-way ANOVA, group (ALS vs. controls): $0.09<P<0.98$; SEPs (N9 vs. N20 vs. P25 vs. N30 vs. N60 vs. P100: $P<0.001$; interaction (group x SEP): $0.52<P<0.96$ ). The SEP modulation was not associated with changes in background EEG activity and component latency. Moreover, conduction time through the somatosensory pathway was found to be unaltered (see Iglesias et al., 2015).

\section{Insert Table 2}

Since we did not observe any difference in peak onset and duration for each SEP component between the study groups, the area of each potential was estimated using a fixed analysis window. Box plot charts in Figure 2 represent the data distribution for potential area (normalized to 2 x SD prestimulus activity) in controls (dark) and in ALS patients (grey) for median and ulnar nerves. N9 and cortical SEP mean areas were found significantly reduced in the patient group compared to controls (Kruskal-Wallis, $P<0.001$ for median and ulnar nerves). In controls, we observed that SEP area increased gradually from N9 to early cortical potentials (N20, P25, N30) while late cortical potentials (N60, P100) exhibited a significant increment. Moreover, we noted that in ALS patients late cortical potentials (N60, P100) exhibited a more significant reduction compared to N9 and early cortical potentials. These findings suggest that all SEP components were altered in ALS patients, and it seems that late SEPs (N60 and P100) were particularly reduced compared to N9, N20, P25 and N30.

\section{Insert Figure 2}

To investigate this notion in more detail, the level of SEP change observed in each patient has been estimated for each component and each nerve, by using the mean results in control group as reference values (see equation in Methods; Fig. 3). The difference from control data, for N9 and cortical SEPs in patient, was then expressed as a percentage of mean N9 (dark) or mean N20 (grey) in controls, respectively. Figure 3 shows that depression in patients was significantly different between components, for each nerve (Kruskal-Wallis, $P<$ 0.001 and $<0.01$ for median and ulnar nerves, respectively). Post-hoc comparisons revealed that, in each nerve, N9 and early cortical SEPs (N25, P30) were similarly reduced as N20 (Tukey, $P>0.05)$, while late SEPs $($ N60, P100) were significantly more reduced than N20 (Tukey, $P<0.05$ ). Thus, the depression of early cortical SEPs was likely linked to that of peripheral afferent volley (N9). Conversely, the depression of late cortical SEPs seemed less dependent of peripheral afferent volley reductions. 


\section{Insert Figure 3}

In addition, we tested whether the level of depression was correlated between each component. The results were similar for both nerves. The correlation coefficient was not significant when testing the possible correlation between the reduction size of N9 and that of cortical SEPs (Pearson product moment correlation; $-0.05<$ correlation coefficient $<0.28$, $0.06<P<0.9$ ). On the contrary, the depression of N20 area was correlated to that of P25 and N30 $(0.4<$ correlation coefficient $<0.6,0.001<P<0.01)$ but not to that of N60 and P100 $(0.3<$ correlation coefficient $<0.4,0.08<P<0.1)$. Finally, the depression of P25, N30, N60 and P100 also were correlated: $0.5<$ correlation coefficient $<0.8(P<0.01)$. We have observed smaller correlation coefficients between P25, N60 and P100, than between P25 and N30. Overall, we did not observe any correlation between the changes in peripheral and cortical SEPs, but we found the depression of cortical SEPs with a latency $>25 \mathrm{~ms}$ correlated.

Additionally, we have also explored the relationship between the level of SEP change observed in patients and their hand-related motor disability. For this, we used the ALSFRS-r sub-score for hand functions, including writing and feeding (functional score). Moreover, we have added the MMT scores for thumb abduction and distal phalanx flexion of finger III (Table 1). We performed multivariate analyses taking into account the following factors: nerve, SEP latency, hand functional (ALSFR-S sub-score) and MMT scores. We did not find any significant difference between nerves, whose results were thus mixed in the following analysis. Furthermore, the force level and the functional score were moderately correlated (correlation coefficient $=0.5, P<0.05)$. The factor 'latency' had a significant influence $(P<$ 0.01) and the link with motor deficits was quite different according to the clinical scale used. Indeed, the functional score for hand movements (ALSFRS-r sub-score) did not have significant influence and the interaction with the factor 'latency' was not significant either. On the contrary, the muscle strength had no significant influence but the interaction with the factor 'latency' was significant $(0.01<P<0.05)$. These results further confirm that the change in SEP area in patients was different according to the SEP latency, and this was particularly related to the depression of hand force but not to the alteration of hand functions. Therefore, to further investigate the relationships with alteration of functional tasks, we performed the same multivariate analyses taking the full score to ALSFRS-r, and we found a significant influence of this score $(P<0.05)$ and a significant interaction with SEP latencies (ALSFR-S x latency, $P<0.001$ ). Figure 4 illustrates the change in SEP area according to the force level (A), the functional clinical score for hand movements (B) or the total ALSFRS-r 
score (C). The modification of the different SEP components (early SEPs represented by the grey symbols, and late SEP, by the black ones) overlapped whatever the hand functional score (Fig. 4B), while late SEPs were more depressed than early ones when the force level was depressed (compare score 5-6 to 8-9; Fig. 4A) or with alteration of day life functions (ALSFR-S < 38-40; Fig. 4C).

\section{Insert Figure 4}

\section{Discussion}

The present study brings new evidence for late cortical SEP alterations induced by median and ulnar nerves stimulation in ALS. Indeed, N60 and P100 were more depressed than the peripheral component N9 and early cortical responses such as N20, P25 and N30. Moreover, the degree of depression correlated only for SEPs with latencies above $25 \mathrm{~ms}$. Finally, the SEP alteration was linked to the depression of hand muscle force and global alteration of day life functions, especially for late SEPs, but not to specific alteration of hand functions.

\subsection{SEP alteration in ALS}

SEP investigation performed in ALS to date mainly focused on early components such as N9, N20 and P25 and by performing median nerve stimulation only. These studies have revealed abnormalities in $35 \%$ patients (Matheson et al., 1986; Radtke et al., 1986; Constantinovici, 1993). The reported alterations included a delayed peak latency with reduction of central and peripheral conduction velocity for $40 \%$ and $20 \%$ patients, respectively, and reduced amplitude for $20 \%$ patients (Anziska and Cracco, 1983; Cosi et al., 1984; Dasheiff et al., 1985; Matheson et al., 1986; Subramaniam and Yiannikas, 1990; Zanette et al., 1990; Shefner et al., 1991; Gregory et al., 1993; Georgesco et al., 1994; Pugdahl et al., 2006; Hammad et al., 2007). In this present study, we did not find any difference in peak onset and latency between groups, reflecting a normal conduction velocity through large-diameter fibres and normal mean conduction velocity, respectively (Parain and Delapierre, 1991; Tanosaki et al., 1999; Shiga et al., 2001). However, we confirm evidence of consistently reduced SEPs, especially the late ones that have been understudied in ALS to date. Moreover, we showed that SEPs were altered for both median and ulnar nerves, the later seldom tested when studying SEPs. The differences compared to previous studies, in terms of proportion of patients with altered SEPs (60\% in the present group, reaching $80 \%$ when 
coupling with spinal diffusion MRI; Iglesias et al., 2015), could be explained by i) the extracephalic reference (ear lobe) we used, which is free from EEG distortions (Stephenson and Gibbs, 1951; Facco et al., 1989; Essl and Rappelsberger, 1998; Hu et al., 2012), and ii), EEG normalization (to $2 \times$ SD pre-stimulus activity), which avoids any bias due to recording conditions that is known to influence the inter- and intra-individual comparisons of electrophysiological recordings (Iglesias et al., 2015). Moreover, our recordings indicate that the cortical background activity was similar in both groups, which may have also influenced the results of previous studies (Arieli et al., 1996; Klistorner and Graham, 2001; You et al., 2012). As stated in Iglesias et al., 2015, it appears that SEP alteration in ALS has been underestimated.

\subsection{Neural origins of early and late SEPs}

N9 reflects the stimulation-induced afferent volley captured at the level of the plexus brachialis (Small, 1980; Anziska and Cracco, 1983; Mauguiere et al., 1999; Mauguiere, 2005). As shown previously in the same group of patients (Iglesias et al., 2015), N9 reductions were associated with sensory fibre alterations, likely proprioceptive in origin. Indeed, the depression of N9 was correlated to MRI diffusion changes in the dorsal columns at the cervical level.

N20 results from the activation of thalamo-cortical projections reaching S1 area. Then, $\mathrm{S} 1$ neural networks project through thalamus and parietal posterior area (associative area) to motor and premotor areas to generate P25, and onto the primary and supplementary motor areas to produce N30 (Small, 1980; Anziska and Cracco, 1983; Bosch et al., 1985; Urbano et al., 1997; Mauguiere et al., 1999; Hoshiyama and Kakigi, 2001; Mauguiere, 2005; Papadelis et al., 2011). Given that the depression of N9 and early cortical SEPs (N20, P25 and N30) were similar, we assumed that alterations of early cortical components were primarily driven by impaired peripheral sensory afferents. However, given that inputs/outputs relationships reach a plateau at 2 x MT (Lesser et al., 1979; Huttunen, 1995; Torquati et al., 2002), N20 was likely less sensitive than N9 to the reduction of afferent volley produced at $9 \times \mathrm{PT}$ (corresponding to an intensity a bit higher than 2 x MT, approximately). This suggests that the reduction of early cortical SEPs may involve supplementary alteration, other than the impairment of sensory inputs only. According to the correlation we found between SEP alterations, this might be particularly true for SEPs with latency above $25 \mathrm{~ms}$, which makes sense given the alteration of motor excitability in ALS (see below). Moreover, atrophy of thalamus, S1 area, as well as motor cortex have been consistently reported in ALS (Smith, 
1960; Nihei et al., 1993; Kew et al., 1994; Zanette et al., 1996; Graham et al., 2004; Thivard et al., 2007; Filippini et al., 2010; Verstraete et al., 2010, 2014; Canu et al., 2011; Mochizuki et al., 2011; Chapman et al., 2012; Li et al., 2012; Bede et al., 2013; Chiò et al., 2014; Devine et al., 2015). Furthermore, P25 alteration observed in our study could be associated with motor cortex pathology, which is supported in this patient group by their higher threshold to transcranial magnetic stimulation compared to controls (Sangari et al., 2016). All of these observations suggest that the reduction of cortical SEPs, likely those with latency above 25 ms, may not only result from the loss of peripheral sensory afferents. Indeed, part of the depression was likely due to impaired neural processing of sensory inputs at the cortical and subcortical levels.

Late SEPs include N60 generated in S2 area and P100 produced in central and temporal cortex (Bosch et al., 1985; Mauguiere, 2005). The depression of late SEPs in ALS was stronger compared to that of N9 and early cortical SEPs. The stimulus intensity we used for conditioning was 1.5-2 x above the one producing the maximal size of late SEPs (plateau level), according to the inputs/outputs relationships (Lesser et al., 1979; Huttunen, 1995; Torquati et al., 2002). Therefore, similarly to early cortical components, the greater depression of late SEPs was likely not only related to the impaired sensory afferent inputs and S2 area atrophy (Smith, 1960; Filippini et al., 2010; Verstraete et al., 2014). Late SEPs are involved in higher-order sensorimotor and cognitive functions through insula, and in limbic function through amygdala and hippocampus (Mauguiere et al., 1997; Halgren et al., 1998; Hari and Forss, 1999; Torquati et al., 2002; Eickhoff et al., 2006a, b; Papadelis et al., 2011; Lim et al., 2012). The limbic system is known to influence autonomy and sensorimotor functions (Gloor, 1975; Baltadzhieva et al., 2005). Besides, hippocampus atrophy has been reported in ALS (Takeda et al., 2009; Bede et al., 2013; Westeneng et al., 2015). Moreover, results of neuropsychological tests revealed cognitive impairment in more than $50 \%$ patients (Charles and Swash, 2001; Kiernan et al., 2011; Bede et al., 2013; Ravits, 2014; Vucic et al., 2014; Murphy et al., 2016). Thus, S2 area impairment could manifest in higher-order sensorimotor and cognitive functions alteration. While acknowledging that altered peripheral inputs may impact on the size of late SEPs, we propose that late SEP reductions primarily derive from extra-motor and cortico-subcortical circuitry dysfunction in ALS.

\subsection{Cortico-subcortical alterations}

We found that the depression of SEP area in ALS was similar for N9, reflecting the stimulation-induced peripheral afferent volley, and for the early components of cortical SEPs 
(N20, P25, N30) but we found it stronger for the late components (N60, P100). These results suggest an abnormal relationship between peripheral inputs and cortical outputs. The association between stimulus intensities, i.e. the level of sensory inputs, and the size of SEPs have been previously studied in healthy subjects for SEPs using median nerve stimulation. These studies focused on N9 and N20 only or on both early and late SEPs but without discriminating these components (Giblin, 1964; Lesser et al., 1979; Gandevia and Burke, 1984; Huttunen, 1995; Torquati et al., 2002). Moreover, a variety of stimulus intensities were utilised, expressed in volts, amps or other composite measures of perceptual and motor thresholds (MT), making it difficult to compare modulation of SEPs according to the stimulus intensity. However, the results can be synthesised as follows: i) N9 increases linearly with the stimulus intensity due to the progressive intensity-related increased of peripheral afferent volley; and ii) the inputs/outputs relationships for N20 and late SEPs reach a plateau level at about 2 and $1.5 \times$ MT, respectively, i.e. at lower stimulus intensities compared to N9. It has been proposed that this result was likely due to a differential recruitment of peripheral fibres and/or an occlusive phenomenon occurring at the central level, in the sub-cortical nuclei relaying the sensory inputs to the cerebral cortex (Lesser et al., 1979; Gandevia and Burke, 1984; Parain and Delapierre, 1991; Huttunen, 1995; Torquati et al., 2002; Lim et al., 2012). Moreover, a loss of N60 has been reported with a relative conservation of N9 potential and early cortical potentials in ALS (Cosi et al., 1984; Bosch et al., 1985; Dasheiff et al., 1985). In this present study, we have identified a correlation between the levels of depression only for SEPs with latency above $25 \mathrm{~ms}$. All these results suggest that the sensory inputs likely have a smaller impact on late cortical components, whose size may thus mainly depend on the activity of cortico-subcortical networks underlying the late cortical responses to sensory inputs. The exact relationship between late SEPs and peripheral inputs remains to be established. Further studies are required using combined electrophysiology and neuroimaging to fully characterise the specific contribution of sensory inputs and cortico-subcortical networks to late cortical responses.

\subsection{Cortical excitability in ALS and link with motor dysfunctions}

Alteration of cortical excitability in ALS has been mainly studied in motor cortex using transcranial magnetic stimulation. It is now well established that cortical excitability impacts on motor thresholds and intra-cortical inhibition (Mills and Nithi, 1997; Eisen and Swash, 2001; Zanette et al., 2002a, b; de Carvalho et al., 2003; Mills, 2003; Vucic et al., 2008; Floyd et al., 2009; Menon et al., 2015a, b). It has been reported that resting motor 
threshold was unaltered, increased or decreased, associated with an unchanged, reduced or reinforced intra-cortical inhibition, respectively. These results led to the notion that cortical excitability evolves from hyper- to hypoexcitability during the progression from the presymptomatic to the symptomatic stage (Eisen et al., 1992, 1996, 1998; Yokota et al., 1996; Ziemann et al., 1997; Weber and Eisen, 2000; Weber et al., 2000; Stewart et al., 2006; Wittstock et al., 2007; Schmied and Attarian, 2008; Attarian et al., 2009; Vucic et al., 2009, 2013; Bae et al., 2014). Moreover, in addition to structural abnormalities affecting the motor cortex, fMRI investigations in ALS patients have revealed functional connectivity impairments through areas of enhanced activation and enhanced connectivity (Douaud et al., 2011; Prell and Grosskreutz, 2013; Chiò et al., 2014; Schmidt et al., 2014; Shen et al., 2015). In particular, both cerebral activity and connectivity have been found to increase in motor and premotor areas, likely due to depressed inhibitory cortical influences (Lloyd et al., 2000; Maekawa, 2004; Turner, 2005; Watanabe et al., 2009; Verstraete et al., 2010; Douaud et al., 2011; Luo et al., 2012; Prell and Grosskreutz, 2013; Shen et al., 2015). Taken together, all of these studies strongly support the concept of depressed synaptic inhibition and excitability changes at the brain level, and motor cortex in particular. The present study brings new evidence for specific alteration of late SEPs, mediated by S2 and associative areas (cf. supra), which suggests that alterations of connectivity, excitability and integrative properties extend to non-motor areas in ALS, as suggested by Mochizuki et al., 2011. The alterations of extramotor areas responsible for higher-order sensori-motor control are likely to be closely linked to motor dysfunction. Indeed, the patients we investigated exhibited mild motor defects that were particularly associated with the alteration of late SEPs: the depression of late SEPs was found to be more constant (and stronger) than early ones, in patients with a more severe hand weakness and/or the lowest global scores to ALSFRS-r, while the change in early SEPs was more uniform whatever the clinical evaluation. Interestingly, the link disappeared when focusing the analysis on specific hand tasks (writing and feeding). These results suggest that the alteration of higher-order cortical pathways involved in cognitive-motor functions (motor programing including prediction of peripheral biofeedback) are not specific to hand muscles, and affect all motor regions implicated in ALS.

\section{Conclusions}

Sensory impairment and altered neural processing in motor and extra-motor areas are likely contributors to ALS pathogenesis. We have demonstrated that alteration of SEPs may also result from an impairment of cortico-subcortical network, involving extra-motor cortical 
network. Moreover, sensory deficits could lead to cortical excitability changes through impaired cortico-subcortical integrative properties, similarly those reported at spinal level (van Zundert et al., 2008; Jiang et al., 2009; Martin and Chang, 2012; Sangari et al., 2016). Thus, ALS should not be considered a pure motor disease, but a complex sensory-motor disease. However, future investigations including neuroimaging are required to further explore the relationship between sensory inputs and cortico-subcortical activities, taking into account the anatomical characteristics of brain structures (underlying the early and late SEPs) and the longitudinal evolution of motor dysfunction.

\section{Figure legends}

Figure 1: Somatosensory evoked potentials.

A) The mean signal ( $\mathrm{N}=600$ frames) is expressed as a $\% 2 \times$ SD the prestimulus activity, and plotted against the latency (ms) after the triggering of median nerve stimulation at wrist level ( 9 x PT). On the left side, the signal was collected at the Erb point and on the right side, over $\mathrm{S} 1$ area (EEG signal, contralateral to the stimulation site). The dark lines illustrate the signals from one control subject and the grey lines, the signals recorded in one ALS patient; the signals from the same control subject and the same patient are illustrated for the Erb point and S1 recordings. The SEPs are indicated on the traces: N9 is indicated on the signal from the Erb point (left side), and the cortical components N20, P25, N30, N60, and P100, are reported on the mean EEG signal (right side). B) Similar recordings as in A were performed in all the 21 patients and the 21 controls, for both median and ulnar nerves. The traces illustrated in B represent the grand average of signals collected in the group of ALS patients (grey line) and in controls (dark line), at the Erb point (left side) or face to S1 area (right side), after median nerve stimulation (upper figurines) and after ulnar nerve stimulation (lower figurines).

Figure 2: Somatosensory evoked potentials area.

Box plot charts showing the data distribution for SEPs area (\% $2 \times$ SD prestimulus) in controls (dark) and in ALS patients (grey): the top and bottom line of the box correspond to the $95 \%$ confidence interval and the line in the box correspond to the median. The two bars extend from the maximum and minimum value. The cross within the box indicates the arithmetical mean which are significantly different between groups for each nerve $(\mathrm{p}<$ $0.001)$.

Figure 3: Somatosensory evoked potentials area reduction in ALS patients. 
Changes in SEP area in ALS patients for the different component evoked from median and ulnar nerves stimulation are expressed in percentage of mean N9 (dark) or N20 (grey) area from controls group. $* \mathrm{p}<0.05$.

Figure 4: Relationships between SEP alteration and motor dysfunctions.

Changes in SEP area in ALS patients (as in Fig. 3) are plotted against the score to clinical evaluation of motor functions including the hand muscle force (muscular testing; A), the ALFR-S sub-score for hand tasks (B), and ALSFR-S total score (C); the lower the score, the stronger the motor dysfunctions.

Table 1: Clinical data

ALSFR-S sub-score for hand functions (/8): sub-score of the revised ALS functional resting scale for hand functions, including writing and feeding with maximal score 8 (4 for each item); ALSFR-S: total score of ALSFR-S (maximal score 48); Hand muscle force (/10): manual muscular testing (MMT) including thumb abduction and distal phalanx flexion of finger III with maximal score 10 (5 for each muscle).

Table 2: Somatosensory evoked potentials latencies and EEG prestimulus activity.

Mean onset and peak latencies (in $\mathrm{ms} \pm \mathrm{SEM}$ ) of each SEPs and mean EEG prestimulus activity (in $\mu \mathrm{V} \pm \mathrm{SEM}$ ) recorded at Erb point and $\mathrm{S} 1$ area are reported in controls (dark) and patients (grey) group for median and ulnar nerves.

\section{$\underline{\text { References }}$}

Allison T, McCarthy G, Wood CC. The relationship between human long-latency somatosensory evoked potentials recorded from the cortical surface and from the scalp. Electroencephalogr. Clin. Neurophysiol. Potentials Sect. 1992; 84: 301-314.

Anziska BJ, Cracco RQ. Short-latency somatosensory evoked potentials to median nerve stimulation in patients with diffuse neurologic disease. Neurology 1983; 33: 989-993.

Arieli A, Sterkin A, Grinvald A, Aertsen AD. Dynamics of ongoing activity: explanation of the large variability in evoked cortical responses. Science 1996; 273: 1868-1871.

Aspell JE, Palluel E, Blanke O. Early and late activity in somatosensory cortex reflects changes in bodily self-consciousness: An evoked potential study. Neuroscience 2012; 216: $110-122$. 
Attarian S, Pouget J, Schmied A. Changes in cortically induced inhibition in amyotrophic lateral sclerosis with time. Muscle Nerve 2009; 39: 310-317.

Bae JS, Menon P, Mioshi E, Kiernan MC, Vucic S. Cortical hyperexcitability and the splithand plus phenomenon: Pathophysiological insights in ALS. Amyotroph. Lateral Scler. Front. Degener. 2014; 15: 250-256.

Baltadzhieva R, Gurevich T, Korczyn AD. Autonomic impairment in amyotrophic lateral sclerosis. Curr. Opin. Neurol. 2005; 18: 487-493.

Bede P, Elamin M, Byrne S, McLaughlin RL, Kenna K, Vajda A, et al. Basal ganglia involvement in amyotrophic lateral sclerosis. Neurology 2013; 81: 2107-2115.

Bosch EP, Yamada T, Kimura J. Somatosensory evoked potentials in motor neuron disease. Muscle Nerve 1985; 8: 556-562.

Bradley WG, Good P, Rasool CG, Adelman LS. Morphometric and biochemical studies of peripheral nerves in amyotrophic lateral sclerosis. Ann. Neurol. 1983; 14: 267-277.

Canu E, Agosta F, Riva N, Sala S, Prelle A, Caputo D, et al. The Topography of Brain Microstructural Damage in Amyotrophic Lateral Sclerosis Assessed Using Diffusion Tensor MR Imaging. Am. J. Neuroradiol. 2011; 32: 1307-1314.

de Carvalho M, Swash M. Nerve conduction studies in amyotrophic lateral sclerosis. Muscle Nerve 2000; 23: 344-352.

de Carvalho M, Turkman A, Swash M. Motor responses evoked by transcranial magnetic stimulation and peripheral nerve stimulation in the ulnar innervation in amyotrophic lateral sclerosis: the effect of upper and lower motor neuron lesion. J. Neurol. Sci. 2003; 210: 8390.

Chapman MC, Jelsone-Swain L, Fling BW, Johnson TD, Gruis K, Welsh RC. Corpus callosum area in amyotrophic lateral sclerosis. Amyotroph. Lateral Scler. 2012; 13: 589591.

Chapman MC, Jelsone-Swain L, Johnson TD, Gruis KL, Welsh RC. Diffusion tensor MRI of the corpus callosum in amyotrophic lateral sclerosis: DTI of the Corpus Callosum in ALS. J. Magn. Reson. Imaging 2014; 39: 641-647.

Charles T, Swash M. Amyotrophic lateral sclerosis: current understanding. J. Neurosci. Nurs. J. Am. Assoc. Neurosci. Nurses 2001; 33: 245-253.

Chiò A, Pagani M, Agosta F, Calvo A, Cistaro A, Filippi M. Neuroimaging in amyotrophic lateral sclerosis: insights into structural and functional changes. Lancet Neurol. 2014; 13: $1228-1240$. 
Cohen-Adad J, El Mendili M-M, Morizot-Koutlidis R, Lehéricy S, Meininger V, Blancho S, et al. Involvement of spinal sensory pathway in ALS and specificity of cord atrophy to lower motor neuron degeneration. Amyotroph. Lateral Scler. Front. Degener. 2013; 14: 30-38.

Constantinovici A. Abnormal somatosensory evoked potentials in amyotrophic lateral sclerosis. Romanian J. Neurol. Psychiatry Rev. Roum. Neurol. Psychiatr. 1993; 31: 273278.

Cosi V, Poloni M, Mazzini L, Callieco R. Somatosensory evoked potentials in amyotrophic lateral sclerosis. J. Neurol. Neurosurg. Psychiatry 1984; 47: 857-861.

Dasheiff RM, Drake ME, Brendle A, Erwin CW. Abnormal somatosensory evoked potentials in amyotrophic lateral sclerosis. Electroencephalogr. Clin. Neurophysiol. 1985; 60: 306311.

Devine MS, Pannek K, Coulthard A, McCombe PA, Rose SE, Henderson RD. Exposing asymmetric gray matter vulnerability in amyotrophic lateral sclerosis. NeuroImage Clin. $2015 ; 7: 782-787$.

Douaud G, Filippini N, Knight S, Talbot K, Turner MR. Integration of structural and functional magnetic resonance imaging in amyotrophic lateral sclerosis. Brain J. Neurol. 2011; 134: 3470-3479.

Drechsler F. Short and long latency cortical potentials following trigeminal nerve stimulation in man. In: Barber C. Evoked potentials. Lancaster: MTP Press Limited; 1980.

Dyck PJ, Stevens JC, Mulder DW, Espinosa RE. Frequency of nerve fiber degeneration of peripheral motor and sensory neurons in amyotrophic lateral sclerosis. Morphometry of deep and superficial peroneal nerves. Neurology 1975; 25: 781-785.

Eickhoff SB, Heim S, Zilles K, Amunts K. Testing anatomically specified hypotheses in functional imaging using cytoarchitectonic maps. NeuroImage 2006a; 32: 570-582.

Eickhoff SB, Lotze M, Wietek B, Amunts K, Enck P, Zilles K. Segregation of visceral and somatosensory afferents: An fMRI and cytoarchitectonic mapping study. NeuroImage $2006 b ; 31: 1004-1014$.

Eisen A, Entezari-Taher M, Stewart H. Cortical projections to spinal motoneurons: changes with aging and amyotrophic lateral sclerosis. Neurology 1996; 46: 1396-1404.

Eisen A, Kim S, Pant B. Amyotrophic lateral sclerosis (ALS): a phylogenetic disease of the corticomotoneuron? Muscle Nerve 1992; 15: 219-224.

Eisen A, Nakajima M, Weber M. Corticomotorneuronal hyper-excitability in amyotrophic lateral sclerosis. J. Neurol. Sci. 1998; 160: S64-S68. 
Eisen A, Swash M. Clinical neurophysiology of ALS. Clin. Neurophysiol. 2001; 112: 21902201.

Essl MM, Rappelsberger P. EEG cohererence and reference signals: experimental results and mathematical explanations. Med. Biol. Eng. Comput. 1998; 36: 399-406.

Facco E, Micaglio G, Liviero MC, Ceccato MB, Toffoletto F, Martinuzzi A, et al. Sensorymotor conduction time in amyotrophic lateral sclerosis. Riv. Neurol. 1989; 59: 108-112.

Feller TG, Jones RE, Netsky MG. Amyotrophic lateral sclerosis and sensory changes. Va. Med. Mon. 1966; 93: 328-335.

Filippini N, Douaud G, Mackay CE, Knight S, Talbot K, Turner MR. Corpus callosum involvement is a consistent feature of amyotrophic lateral sclerosis. Neurology 2010; 75: $1645-1652$.

Fincham RW, Van Allen MW. Sensory nerve conduction in amyotrophic lateral sclerosis. Neurology 1964; 14: 31-31.

Fischer LR, Culver DG, Davis AA, Tennant P, Wang M, Coleman M, et al. The WldS gene modestly prolongs survival in the SOD1G93A fALS mouse. Neurobiol. Dis. 2005; 19: 293300 .

Floyd AG, Yu QP, Piboolnurak P, Tang MX, Fang Y, Smith WA, et al. Transcranial magnetic stimulation in ALS: utility of central motor conduction tests. Neurology 2009; 72: 498-504.

Gandevia SC, Burke D. Saturation in human somatosensory pathways. Exp. Brain Res. 1984; 54: $582-585$.

Georgesco M, Salerno A, Carlander B, Léger JJ, Camu W, Billiard M, et al. [Somatosensory evoked potentials in amyotrophic lateral sclerosis and primary lateral sclerosis]. Rev. Neurol. (Paris) 1994; 150: 292-298.

Giblin DR. Somatosensory evoked potentials in healthy subjects and in patients with lesions of the nervous system. Ann. N. Y. Acad. Sci. 1964; 112: 93-142.

Gloor P. Physiology of the limbic system. Adv. Neurol. 1975; 11: 27-55.

Graham JM, Papadakis N, Evans J, Widjaja E, Romanowski C a. J, Paley MNJ, et al. Diffusion tensor imaging for the assessment of upper motor neuron integrity in ALS. Neurology 2004; 63: 2111-2119.

Gregory R, Mills K, Donaghy M. Progressive sensory nerve dysfunction in amyotrophic lateral sclerosis: a prospective clinical and neurophysiological study. J. Neurol. 1993; 240: 309-314.

Halgren E, Marinkovic K, Chauvel P. Generators of the late cognitive potentials in auditory and visual oddball tasks. Electroencephalogr. Clin. Neurophysiol. 1998; 106: 156-164. 
Hammad M, Silva A, Glass J, Sladky JT, Benatar M. Clinical, electrophysiologic, and pathologic evidence for sensory abnormalities in ALS. Neurology 2007; 69: 2236-2242.

Hari R, Forss N. Magnetoencephalography in the study of human somatosensory cortical processing. Philos. Trans. R. Soc. B Biol. Sci. 1999; 354: 1145-1154.

Heads T, Pollock M, Robertson A, Sutherland WHF, Allpress S. Sensory nerve pathology in amyotrophic lateral sclerosis. Acta Neuropathol. (Berl.) 1991; 82: 316-320.

Hoshiyama M, Kakigi R. Correspondence between short-latency somatosensory evoked brain potentials and cortical magnetic fields following median nerve stimulation. Brain Res. 2001; 908: $140-148$.

Hu S, Cao Y, Chen S, Zhang J, Kong W, Yang K, et al. A comparative study of two reference estimation methods in EEG recording [Internet]. In: Advances in Brain Inspired Cognitive Systems. Springer; 2012. p. 321-328. [cited 2016 May 27] Available from: http://link.springer.com/chapter/10.1007/978-3-642-31561-9_36

Huttunen J. Effects of stimulus intensity on frontal, central and parietal somatosensory evoked potentials after median nerve stimulation. Electromyogr. Clin. Neurophysiol. 1995; 35: 217223.

Iglesias C, Sangari S, El Mendili M-M, Benali H, Marchand-Pauvert V, Pradat P-F. Electrophysiological and spinal imaging evidences for sensory dysfunction in amyotrophic lateral sclerosis. BMJ Open 2015; 5: e007659-e007659.

Isak B, Tankisi H, Johnsen B, Pugdahl K, Møller AT, Finnerup NB, et al. Involvement of distal sensory nerves in amyotrophic lateral sclerosis: Sensory nerves in motor neuron disease [Internet]. Muscle Nerve 2016[cited 2016 May 27] Available from: http://doi.wiley.com/10.1002/mus.25157

Jiang M, Schuster JE, Fu R, Siddique T, Heckman CJ. Progressive changes in synaptic inputs to motoneurons in adult sacral spinal cord of a mouse model of amyotrophic lateral sclerosis. J. Neurosci. Off. J. Soc. Neurosci. 2009; 29: 15031-15038.

Kawamura Y, Dyck PJ, Shimono M, Okazaki H, Tateishi J, Doi H. Morphometric comparison of the vulnerability of peripheral motor and sensory neurons in amyotrophic lateral sclerosis. J. Neuropathol. Exp. Neurol. 1981; 40: 667-675.

Kew JJM, Brooks DJ, Passingham RE, Rothwell JC, Frackowiak RSJ, Leigh PN. Cortical function in progressive lower motor neuron disorders and amyotrophic lateral sclerosis $\mathrm{A}$ comparative PET study. Neurology 1994; 44: 1101-1101.

Kiernan MC, Vucic S, Cheah BC, Turner MR, Eisen A, Hardiman O, et al. Amyotrophic lateral sclerosis. The Lancet 2011; 377: 942-955. 
Klistorner AI, Graham SL. Electroencephalogram-based scaling of multifocal visual evoked potentials: effect on intersubject amplitude variability. Invest. Ophthalmol. Vis. Sci. 2001; 42: $2145-2152$.

Lesser RP, Koehle R, Lueders H. Effect of stimulus intensity on short latency somatosensory evoked potentials. Electroencephalogr. Clin. Neurophysiol. 1979; 47: 377-382.

Li J, Pan P, Song W, Huang R, Chen K, Shang H. A meta-analysis of diffusion tensor imaging studies in amyotrophic lateral sclerosis. Neurobiol. Aging 2012; 33: 1833-1838.

Lim M, Kim JS, Chung CK. Modulation of somatosensory evoked magnetic fields by intensity of interfering stimuli in human somatosensory cortex: An MEG study. NeuroImage 2012; 61: 660-669.

Lloyd CM, Richardson MP, Brooks DJ, Al-Chalabi A, Leigh PN. Extramotor involvement in ALS: PET studies with the GABAA ligand [11C] flumazenil. Brain 2000; 123: 2289-2296.

Luo C, Chen Q, Huang R, Chen X, Chen K, Huang X, et al. Patterns of spontaneous brain activity in amyotrophic lateral sclerosis: a resting-state FMRI study. PloS One 2012; 7 : e45470.

Maekawa S. Cortical selective vulnerability in motor neuron disease: a morphometric study. Brain 2004; 127: 1237-1251.

Martin LJ, Chang Q. Inhibitory Synaptic Regulation of Motoneurons: A New Target of Disease Mechanisms in Amyotrophic Lateral Sclerosis. Mol. Neurobiol. 2012; 45: 30-42.

Matheson JK, Harrington HJ, Hallett M. Abnormalities of multimodality evoked potentials in amyotrophic lateral sclerosis. Arch. Neurol. 1986; 43: 338-340.

Mauguiere F. Somatosensory Evoked Potentials: Normal Responses, Abnormal Waveforms, and Clinical Applications in Neurological Diseases. In: Niedermeyer E. and Lopes da Silva F. Electroencephalography: basic principles, clinical applications, and related fields. 5. ed. Philadelphia: Lippincott Williams \& Wilkins; 2005.

Mauguiere F, Allison T, Babiloni C, Buchner H, Eisen AA, Goodin DS, et al. Somatosensory evoked potentials. The International Federation of Clinical Neurophysiology. Electroencephalogr. Clin. Neurophysiol. Suppl. 1999; 52: 79-90.

Mauguiere F, Merlet I, Forss N, Vanni S, Jousmäki V, Adeleine P, et al. Activation of a distributed somatosensory cortical network in the human brain. A dipole modelling study of magnetic fields evoked by median nerve stimulation. Part I: Location and activation timing of SEF sources. Electroencephalogr. Clin. Neurophysiol. Potentials Sect. 1997; 104: 281289. 
Menon P, Geevasinga N, Yiannikas C, Howells J, Kiernan MC, Vucic S. Sensitivity and specificity of threshold tracking transcranial magnetic stimulation for diagnosis of amyotrophic lateral sclerosis: a prospective study. Lancet Neurol. 2015a; 14: 478-484.

Menon P, Kiernan MC, Vucic S. Cortical hyperexcitability precedes lower motor neuron dysfunction in ALS. Clin. Neurophysiol. 2015b; 126: 803-809.

Mills KR. The natural history of central motor abnormalities in amyotrophic lateral sclerosis. Brain 2003; 126: 2558-2566.

Mills KR, Nithi KA. Corticomotor threshold is reduced in early sporadic amyotrophic lateral sclerosis. Muscle Nerve 1997; 20: 1137-1141.

Mochizuki Y, Mizutani T, Shimizu T, Kawata A. Proportional neuronal loss between the primary motor and sensory cortex in amyotrophic lateral sclerosis. Neurosci. Lett. 2011; 503: 73-75.

Mondelli M, Rossi A, Passero S, Guazzi GC. Involvement of peripheral sensory fibers in amyotrophic lateral sclerosis: electrophysiological study of 64 cases. Muscle Nerve 1993; 16: $166-172$.

Mulder DW, Bushek W, Spring E, Karnes J, Dyck PJ. Motor neuron disease (ALS): evaluation of detection thresholds of cutaneous sensation. Neurology 1983; 33: 1625-1627.

Murphy J, Factor-Litvak P, Goetz R, Lomen-Hoerth C, Nagy PL, Hupf J, Singleton J, Woolley S, Andrews H, Heitzman D, Bedlack RS, Katz JS, Barohn RJ, Sorenson EJ, Oskarsson B, Fernandes Filho JA, Kasarskis EJ, Mozaffar T, Rollins YD, Nations SP, Swenson AJ, Koczon-Jaremko BA, Mitsumoto H; ALS COSMOS. Cognitive-behavioral screening reveals prevalent impairment in a large multicenter ALS cohort. Neurology 2016; 86: $813-820$.

Nihei K, McKee AC, Kowall NW. Patterns of neuronal degeneration in the motor cortex of amyotrophic lateral sclerosis patients. Acta Neuropathol. (Berl.) 1993; 86: 55-64.

Oldfield RC. The assessment and analysis of handedness: the Edinburgh inventory. Neuropsychologia 1971; 9: 97-113.

Papadelis C, Eickhoff SB, Zilles K, Ioannides AA. BA3b and BA1 activate in a serial fashion after median nerve stimulation: Direct evidence from combining source analysis of evoked fields and cytoarchitectonic probabilistic maps. NeuroImage 2011; 54: 60-73.

Parain D, Delapierre G. Effects of stimulus intensity increase on short-latency somatosensory evoked potentials: application of polynomial curvature coefficients. Brain Topogr. 1991; 4: 31-35. 
Prell T, Grosskreutz J. The involvement of the cerebellum in amyotrophic lateral sclerosis. Amyotroph. Lateral Scler. Front. Degener. 2013; 14: 507-515.

Pugdahl K, Fuglsang-Frederiksen A, de Carvalho M, Johnsen B, Fawcett PRW, Labarre-Vila A, et al. Generalised sensory system abnormalities in amyotrophic lateral sclerosis: a European multicentre study. J. Neurol. Neurosurg. Psychiatry 2006; 78: 746-749.

Radtke RA, Erwin A, Erwin CW. Abnormal sensory evoked potentials in amyotrophic lateral sclerosis. Neurology 1986; 36: 796-801.

Ravits J. Focality, stochasticity and neuroanatomic propagation in ALS pathogenesis. Exp. Neurol. 2014; 262: 121-126.

Sábado J, Casanovas A, Tarabal O, Hereu M, Piedrafita L, Calderó J, et al. Accumulation of Misfolded SOD1 in Dorsal Root Ganglion Degenerating Proprioceptive Sensory Neurons of Transgenic Mice with Amyotrophic Lateral Sclerosis. BioMed Res. Int. 2014; 2014: 1-13.

Sangari S, Iglesias C, El Mendili M-M, Benali H, Pradat P-F, Marchand-Pauvert V. Impairment of sensory-motor integration at spinal level in amyotrophic lateral sclerosis. Clin. Neurophysiol. 2016; 127: 1968-1977.

Saradjian AH, Tremblay L, Perrier J, Blouin J, Mouchnino L. Cortical facilitation of proprioceptive inputs related to gravitational balance constraints during step preparation. J. Neurophysiol. 2013; 110: 397-407.

Schmidt R, Verstraete E, de Reus MA, Veldink JH, van den Berg LH, van den Heuvel MP. Correlation between structural and functional connectivity impairment in amyotrophic lateral sclerosis. Hum. Brain Mapp. 2014; 35: 4386-4395.

Schmied A, Attarian S. Enhancement of single motor unit inhibitory responses to transcranial magnetic stimulation in amyotrophic lateral sclerosis. Exp. Brain Res. 2008; 189: 229-242.

Schulte-Mattler WJ, Jakob M, Zierz S. Focal sensory nerve abnormalities in patients with amyotrophic lateral sclerosis. J. Neurol. Sci. 1999; 162: 189-193.

Shahani M, Bharucha EP, and Capadia GP. Comparative study of early and late somatosensory evoked potentials in patients with hemiplegia and/or hemianaesthesia. In: Barber C. Evoked potentials. Lancaster: MTP Press Limited; 1980.

Shefner JM, Tyler HR, Krarup C. Abnormalities in the sensory action potential in patients with amyotrophic lateral sclerosis. Muscle Nerve 1991; 14: 1242-1246.

Shen D, Cui L, Cui B, Fang J, Li D, Ma J. A Systematic Review and Meta-Analysis of the Functional MRI Investigation of Motor Neuron Disease. Front. Neurol. 2015; 6: 246. 
Shiga Y, Yamada T, Ofuji A, Fujita Y, Kawamura T, Inoue K, et al. Effects of stimulus intensity on latency and conduction time of short-latency somatosensory evoked potentials. Clin. EEG Electroencephalogr. 2001; 32: 75-81.

Small DG. Somatosensory and spinal evoked potentials. In: Barber C. Evoked potentials. Lancaster: MTP Press Limited; 1980.

Smith MC. Nerve fibre degeneration in the brain in amyotrophic lateral sclerosis. J. Neurol. Neurosurg. Psychiatry 1960; 23: 269-282.

Stephenson WA, Gibbs FA. A balanced non-cephalic reference electrode. Electroencephalogr. Clin. Neurophysiol. 1951; 3: 237-240.

Stewart HG, Andersen PM, Eisen A, Weber M. Corticomotoneuronal dysfunction in ALS patients with different SOD1 mutations. Clin. Neurophysiol. 2006; 117: 1850-1861.

Subramaniam JS, Yiannikas C. Multimodality evoked potentials in motor neuron disease. Arch. Neurol. 1990; 47: 989-994.

Swash M, Scholtz C.L, Vowles G, \& Ingram DA. Selective and Asymmetric Vulnerability of Corticospinal and Spinocerebellar Tracts in Motor Neuron Disease. J Neurol Neurosurg Psychiatry. 1988; 51: 785-89.

Takahashi H, Oyanagi K, Ohama E, \& Ikuta F. Clarke's Column in Sporadic Amyotrophic Lateral Sclerosis. Acta Neuropathologica. 1992; 84: 465-70.

Takeda T, Uchihara T, Arai N, Mizutani T, Iwata M. Progression of hippocampal degeneration in amyotrophic lateral sclerosis with or without memory impairment: distinction from Alzheimer disease. Acta Neuropathol. (Berl.) 2009; 117: 35-44.

Tanosaki M, Ozaki I, Shimamura H, Baba M, Matsunaga M. Effects of aging on central conduction in somatosensory evoked potentials: evaluation of onset versus peak methods. Clin. Neurophysiol. Off. J. Int. Fed. Clin. Neurophysiol. 1999; 110: 2094-2103.

Theys PA, Peeters E, Robberecht W. Evolution of motor and sensory deficits in amyotrophic lateral sclerosis estimated by neurophysiological techniques. J. Neurol. 1999; 246: 438-442.

Thivard L, Pradat P-F, Lehericy S, Lacomblez L, Dormont D, Chiras J, et al. Diffusion tensor imaging and voxel based morphometry study in amyotrophic lateral sclerosis: relationships with motor disability. J. Neurol. Neurosurg. Amp Psychiatry 2007; 78: 889-892.

Tohgi H, Tsukagoshi H, Toyokura Y. Quantitative changes of sural nerves in various neurological diseases. Acta Neuropathol. (Berl.) 1977; 38: 95-101.

Torquati K, Pizzella V, Della Penna S, Franciotti R, Babiloni C, Rossini PM, et al. Comparison between SI and SII responses as a function of stimulus intensity. Neuroreport 2002; 13: 813-819. 
di Trapani G, David P, La Cara A, Servidei S, Tonali P. Morphological studies of sural nerve biopsies in the pseudopolyneuropathic form of amyotrophic lateral sclerosis. Clin. Neuropathol. 1986; 5: 134-138.

Turner MR. [11C]-WAY100635 PET demonstrates marked 5-HT1A receptor changes in sporadic ALS. Brain 2005; 128: 896-905.

Urbano A, Babiloni F, Babiloni C, Ambrosini A, Onorati P, Rossini PM. Human short latency cortical responses to somatosensory stimulation. A high resolution EEG study. Neuroreport 1997; 8: 3239-3243.

Vaughan SK, Kemp Z, Hatzipetros T, Vieira F, Valdez G. Degeneration of proprioceptive sensory nerve endings in mice harboring amyotrophic lateral sclerosis-causing mutations: Proprioceptive Sensory Neurons and ALS. J. Comp. Neurol. 2015; 523: 2477-2494.

Verstraete E, van den Heuvel MP, Veldink JH, Blanken N, Mandl RC, Hulshoff Pol HE, et al. Motor Network Degeneration in Amyotrophic Lateral Sclerosis: A Structural and Functional Connectivity Study. PLoS ONE 2010; 5: e13664.

Verstraete E, Veldink JH, van den Berg LH, van den Heuvel MP. Structural brain network imaging shows expanding disconnection of the motor system in amyotrophic lateral sclerosis: Expanding Motor Disconnection in ALS. Hum. Brain Mapp. 2014; 35: 13511361.

Vucic S, Cheah BC, Kiernan MC. Defining the mechanisms that underlie cortical hyperexcitability in amyotrophic lateral sclerosis. Exp. Neurol. 2009; 220: 177-182.

Vucic S, Lin CS-Y, Cheah BC, Murray J, Menon P, Krishnan AV, et al. Riluzole exerts central and peripheral modulating effects in amyotrophic lateral sclerosis. Brain 2013; 136: 1361-1370.

Vucic S, Nicholson GA, Kiernan MC. Cortical hyperexcitability may precede the onset of familial amyotrophic lateral sclerosis. Brain 2008; 131: 1540-1550.

Vucic S, Rothstein JD, Kiernan MC. Advances in treating amyotrophic lateral sclerosis: insights from pathophysiological studies. Trends Neurosci. 2014; 37: 433-442.

Watanabe S, Kimura T, Suenaga K, Wada S, Tsuda K, Kasama S, et al. Decreased chloride levels of cerebrospinal fluid in patients with amyotrophic lateral sclerosis. J. Neurol. Sci. 2009; 285: 146-148.

Weber M, Eisen A. Peristimulus time histograms (PSTHs)--a marker for upper motor neuron involvement in ALS? Amyotroph. Lateral Scler. Mot. Neuron Disord. Off. Publ. World Fed. Neurol. Res. Group Mot. Neuron Dis. 2000; 1 Suppl 2: S51-56. 
Weber M, Eisen A, Stewart H, Hirota N. The split hand in ALS has a cortical basis. J. Neurol. Sci. 2000; 180: 66-70.

Westeneng H-J, Verstraete E, Walhout R, Schmidt R, Hendrikse J, Veldink JH, et al. Subcortical structures in amyotrophic lateral sclerosis. Neurobiol. Aging 2015; 36: 10751082.

Williams C, Kozlowski M.A, Hinton D.R \& Miller C.A. (1990). Degeneration of Spinocerebellar Neurons in Amyotrophic Lateral Sclerosis. Ann Neurol. 1990; 27: 215-25.

Wittstock M, Wolters A, Benecke R. Transcallosal inhibition in amyotrophic lateral sclerosis. Clin. Neurophysiol. 2007; 118: 301-307.

Woolsey CN, Erickson TC, Gilson WE. Localization in somatic sensory and motor areas of human cerebral cortex as determined by direct recording of evoked potentials and electrical stimulation. J. Neurosurg. 1979; 51: 476-506.

Yokota T, Yoshino A, Inaba A, Saito Y. Double cortical stimulation in amyotrophic lateral sclerosis. J. Neurol. Neurosurg. Psychiatry 1996; 61: 596-600.

You Y, Thie J, Klistorner A, Gupta VK, Graham SL. Normalization of Visual Evoked Potentials Using Underlying Electroencephalogram Levels Improves Amplitude Reproducibility in Rats. Investig. Opthalmology Vis. Sci. 2012; 53: 1473.

Zanette G, Polo A, Gasperini M, Bertolasi L, De Grandis D. Far-field and cortical somatosensory evoked potentials in motor neuron disease. Muscle Nerve 1990; 13: 47-55.

Zanette G, Tamburin S, Manganotti P, Refatti N, Forgione A, Rizzuto N. Different mechanisms contribute to motor cortex hyperexcitability in amyotrophic lateral sclerosis. Clin. Neurophysiol. Off. J. Int. Fed. Clin. Neurophysiol. 2002a; 113: 1688-1697.

Zanette G, Tamburin S, Manganotti P, Refatti N, Forgione A, Rizzuto N. Changes in motor cortex inhibition over time in patients with amyotrophic lateral sclerosis. J. Neurol. 2002b; 249: 1723-1728.

Zanette G, Tinazzi M, Polo A, Rizzuto N. Motor neuron disease with pyramidal tract dysfunction involves the cortical generators of the early somatosensory evoked potential to tibial nerve stimulation. Neurology 1996; 47: 932-938.

Ziemann U, Winter M, Reimers CD, Reimers K, Tergau F, Paulus W. Impaired motor cortex inhibition in patients with amyotrophic lateral sclerosis. Evidence from paired transcranial magnetic stimulation. Neurology 1997; 49: 1292-1298.

van Zundert B, Peuscher MH, Hynynen M, Chen A, Neve RL, Brown RH, et al. Neonatal Neuronal Circuitry Shows Hyperexcitable Disturbance in a Mouse Model of the Adult- 
Onset Neurodegenerative Disease Amyotrophic Lateral Sclerosis. J. Neurosci. 2008; 28: $10864-10874$. 
Table 1

\begin{tabular}{cccc} 
Patient & $\begin{array}{c}\text { ALSFR-S sub-score for } \\
\text { hand functions (/8) }\end{array}$ & ALSFR-S & $\begin{array}{c}\text { Hand muscle force } \\
(\mathbf{1 0})\end{array}$ \\
\hline $\mathbf{1}$ & 4 & 42 & 8 \\
$\mathbf{2}$ & 4 & 42 & 5 \\
$\mathbf{3}$ & 8 & 41 & 8 \\
$\mathbf{4}$ & 6 & 34 & 7 \\
$\mathbf{5}$ & 6 & 43 & 9 \\
$\mathbf{6}$ & 5 & 39 & 8 \\
$\mathbf{7}$ & 8 & 39 & 8 \\
$\mathbf{8}$ & 8 & 40 & 9 \\
$\mathbf{9}$ & 8 & 34 & 8 \\
\hline $\mathbf{1 0}$ & 3 & 37 & 6 \\
$\mathbf{1 1}$ & 3 & 31 & 8 \\
\hline $\mathbf{1 2}$ & 4 & 30 & 6 \\
\hline $\mathbf{1 3}$ & 6 & 41 & 6 \\
\hline $\mathbf{1 4}$ & 7 & 45 & 8 \\
\hline $\mathbf{1 5}$ & 7 & 46 & 8 \\
\hline $\mathbf{1 6}$ & 7 & 44 & 9 \\
\hline $\mathbf{1 7}$ & 6 & 40 & 7 \\
\hline $\mathbf{1 8}$ & 5 & 33 & 8 \\
\hline $\mathbf{1 9}$ & 6 & 40 & 8 \\
\hline $\mathbf{2 0}$ & 6 & 45 & 8 \\
\hline $\mathbf{2 1}$ & 6 & 40 & 8 \\
\hline
\end{tabular}


Table 2

Latency (ms)

Median nerve Ulnar nerve

\begin{tabular}{|c|c|c|c|c|}
\cline { 2 - 5 } \multicolumn{1}{c|}{} & onset & peak & onset & peak \\
\hline N9 & $9.1 \pm 0.2$ & $10.7 \pm 0.2$ & $9.6 \pm 0.2$ & $11.2 \pm 0.2$ \\
& $9.2 \pm 0.2$ & $10.7 \pm 0.2$ & $9.7 \pm 0.2$ & $11.0 \pm 0.2$ \\
\hline N9 & $12.4 \pm 0.2$ & & $12.9 \pm 0.3$ & \\
end & $12.7 \pm 0.3$ & & $12.9 \pm 0.3$ & \\
\hline N20 & $16.0 \pm 0.2$ & $19.0 \pm 0.4$ & $16.2 \pm 0.3$ & $18.7 \pm 0.4$ \\
& $16.4 \pm 0.2$ & $19.4 \pm 0.3$ & $16.7 \pm 0.3$ & $19.1 \pm 0.4$ \\
\hline P25 & $21.2 \pm 0.3$ & $23.5 \pm 0.4$ & $21.2 \pm 0.4$ & $23.5 \pm 0.4$ \\
& $21.9 \pm 0.3$ & $24.0 \pm 0.4$ & $22.2 \pm 0.4$ & $23.9 \pm 0.5$ \\
\hline N30 & $26.6 \pm 0.4$ & $29.1 \pm 0.4$ & $27.0 \pm 0.5$ & $30.1 \pm 0.6$ \\
& $27.2 \pm 0.6$ & $30.2 \pm 0.5$ & $27.5 \pm 0.5$ & $30.6 \pm 0.7$ \\
\hline N30 & $33.0 \pm 0.5$ & & $35.7 \pm 0.7$ & \\
end & $33.3 \pm 0.4$ & & $35.1 \pm 0.7$ & \\
\hline N60 & $43.8 \pm 0.9$ & $55.0 \pm 1.2$ & $51.8 \pm 07$ & $60.8 \pm 0.9$ \\
\hline P100 & $46.3 \pm 1.2$ & $55.7 \pm 1.1$ & $50.0 \pm 1.2$ & $60.0 \pm 1.0$ \\
\hline P100 & $100.7 \pm 1.2$ & $113.5 \pm 2.8$ & $102.3 \pm 1.4$ & $113.1 \pm 1.8$ \\
end & $99.8 \pm 1.5$ & $111.4 \pm 1.9$ & $103.3 \pm 1.5$ & $117.7 \pm 2.0$ \\
\hline
\end{tabular}

Prestimulus activity $(\mu \mathrm{V})$

\begin{tabular}{|c|c|c|}
\hline $\begin{array}{c}\text { Erb } \\
\text { point }\end{array}$ & $1.3 \pm 0.2$ & $1.2 \pm 0.2$ \\
\hline S1 & $2.1 \pm 0.4$ & $2.5 \pm 0.7$ \\
area & $0.4 \pm 0.03$ & $0.4 \pm 0.03$ \\
\hline
\end{tabular}


A
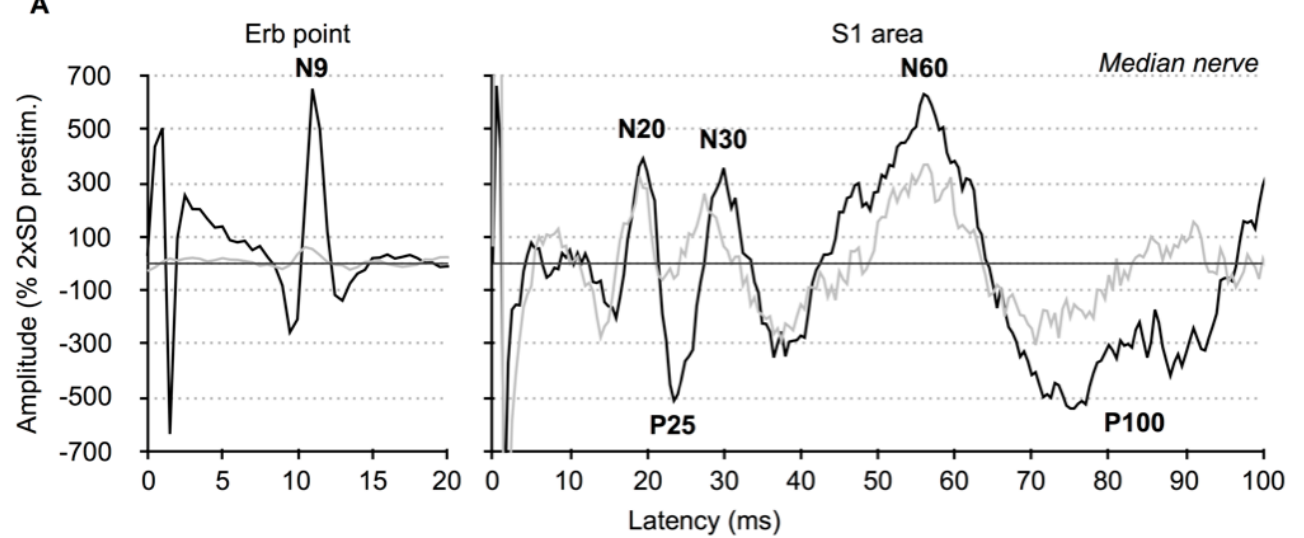

B
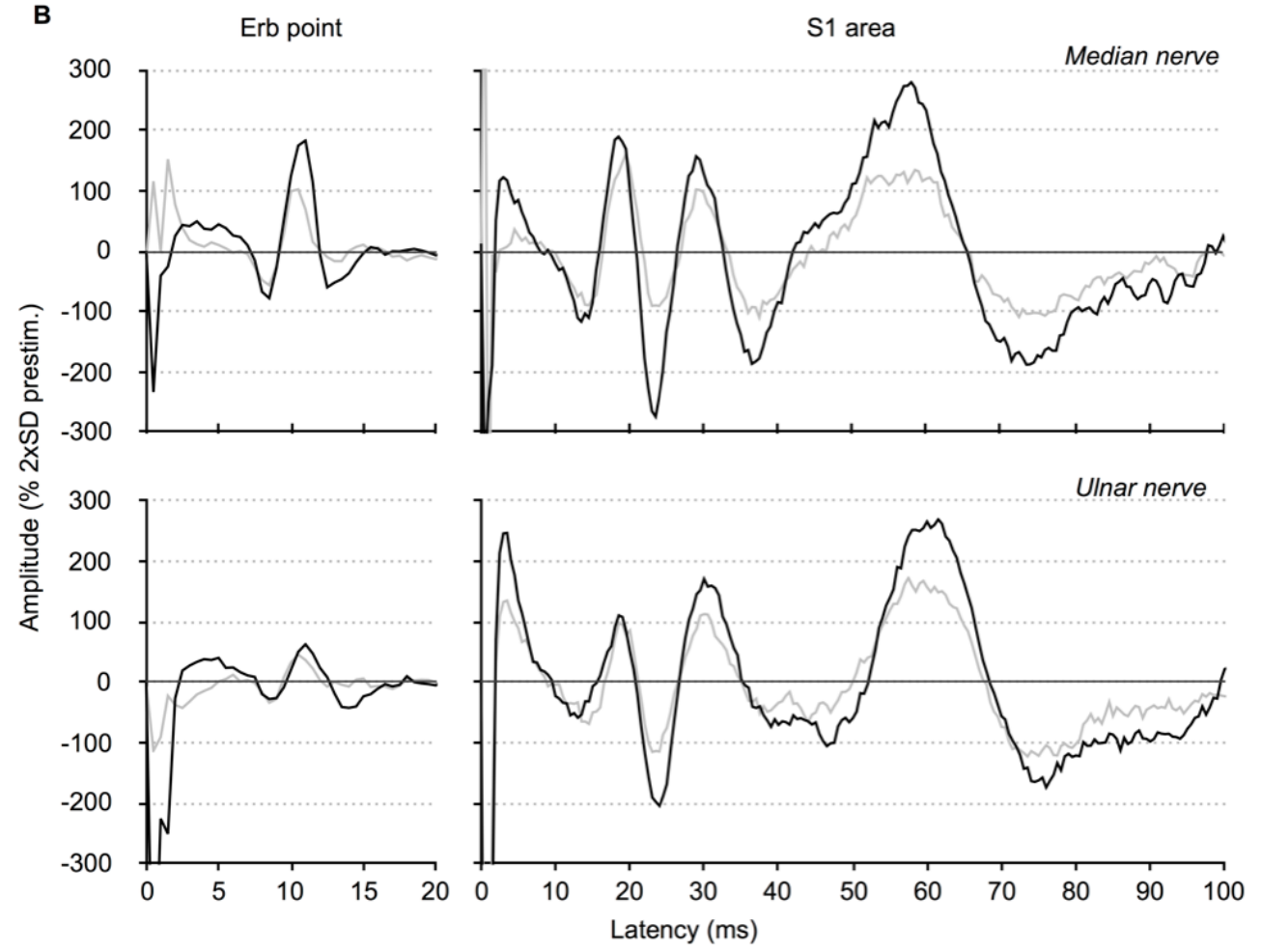

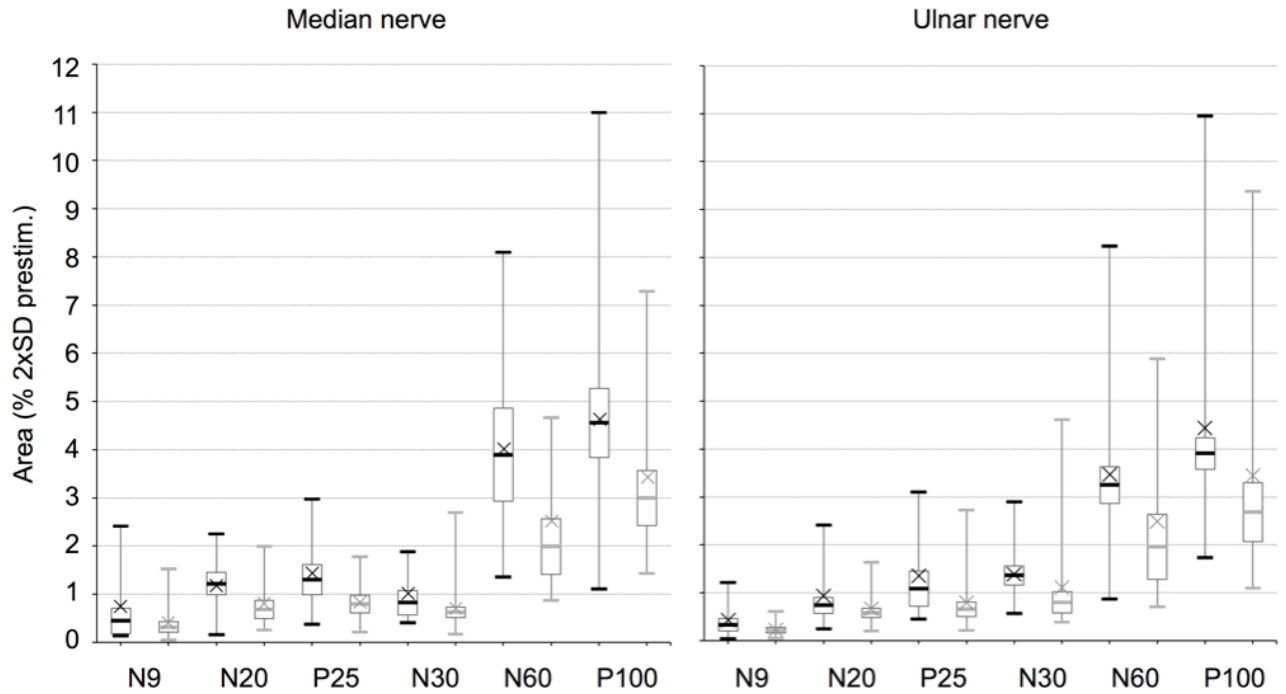
Normalized on mean N9 controls area Normalized on mean N20 controls area
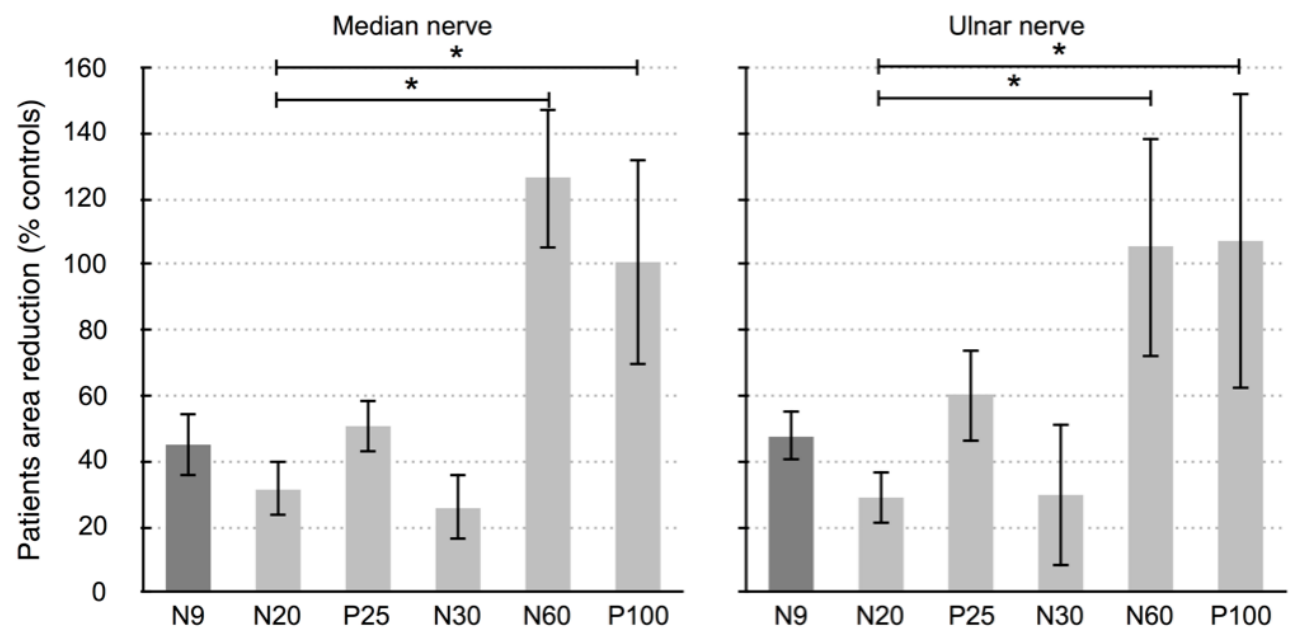

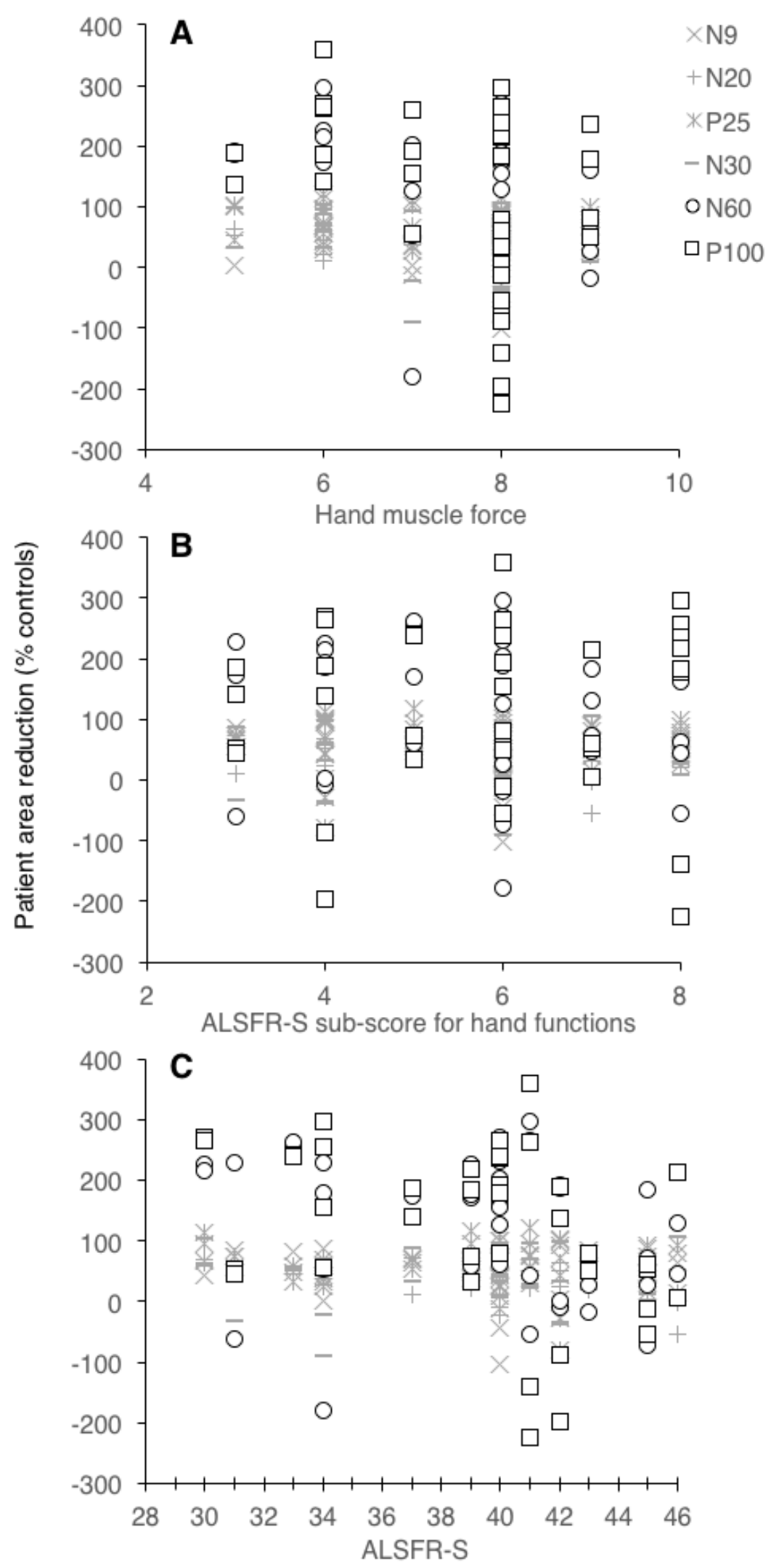